\title{
AN EVIDENCE BASED DEPARMENTAL GUIDELINE FOR PROVISION OF REGIONAL ANAESTEHSIA IN BREAST SURGERY
}

\author{
Dr D Stangoe ${ }^{1}$ Dr R Kanji² and Dr N Courtenay-Evans ${ }^{3}$
}

\begin{abstract}
1. Department of Anaesthetics, Guys and St Thomas NHS Foundation Trust, London
2. Department of Anaesthetics, St Mary's Hospital, Imperial College Healthcare NHS Trust, London

3. Department of Anaesthetics, East Surrey Hospital, Surrey and Sussex Healthcare NHS Trust, Redhill
\end{abstract}

\section{Background}

Regional anaesthesia (RA) in breast surgery (BS) reduces post-operative ${ }^{1,2,3}$ and chronic pain. ${ }^{4}$ However, the possibility of reduced risk of malignant recurrence ${ }^{5,6}$ massively furthers its role in Oncoplastic BS and the importance of the Regional Anaesthetist.

The neuroendocrine response $\mathrm{RA}$ attenuates has multiple pro-malignant effects including depression of cell-mediated immunity, reducing tumour related anti-angiogenic factors and increasing proangiogenic factors. ${ }^{7}$ Additionally, opioids inhibit cellular and humoral immune function, increase angiogenesis and promote breast tumour growth in rodents. A large randomised-control trial assessing if the aforementioned effects of RA translate into reduced long-term recurrence ${ }^{7}$ is due to publish its findings imminently.

Against this background we devised a guideline to increase and standardise the use of RA in oncological BS.

\section{Method}

Google Scholar provided the basis of a literature search. All local Surgeons and Anaesthetists undertaking BS were asked their opinions on RA in BS and their preferred modality thereof. The guideline is thus both evidence based and agreeable to relevant parties.

\section{Guideline Summary}

In all malignant BS, a block should be performed and this block should precede surgery. On account of its simplicity, ${ }^{8}$ superior efficacy, ${ }^{9,10}$ low complication rate and local favour, PECSII should be the block of choice with an additional PECSI subject to Surgeon's agreement. For axillary dissection, Serratus Anterior block can be offered subject to Surgeon's agreement. Paravertebral and Intrapleural blocks are valid alternatives if PECSI\&II are not possible.

\section{Conclusion}

Pain reduction alone justifies promotion and standardisation of RA in BS but if oncological benefit is proven, widespread deployment is essential and the status of RA is appropriately elevated.

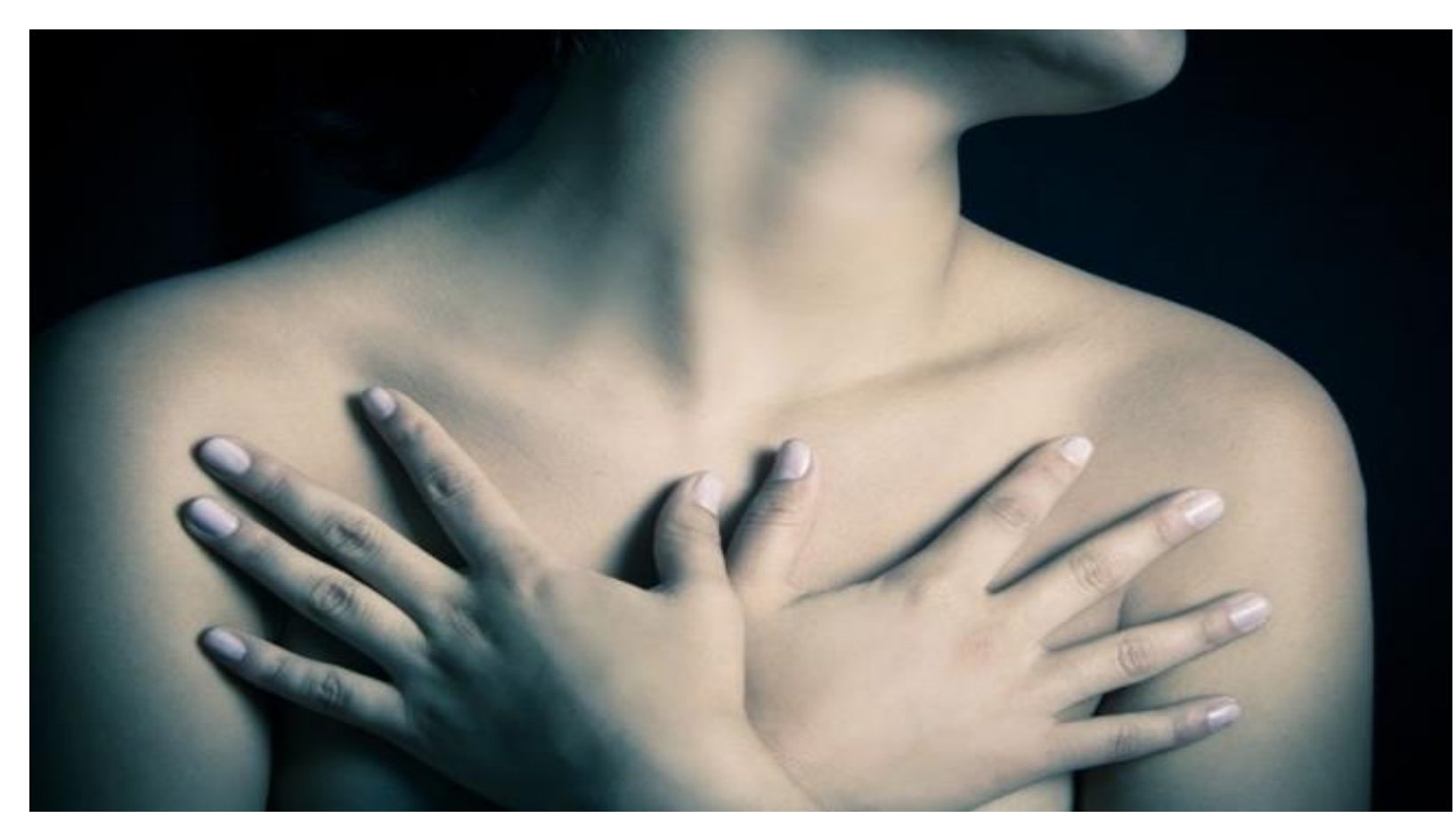

1. Beverly A, Courtney-Evans N, Rudiger J. Analgesia for Breast Surgery: Regional vs. LA infiltration. Poster Presentation ESRA Annual Conference 2017.

2. Moller, JF, Nikolajsen, L, Rodt, SA, et al. Thoracic paravertebral block for breast cancer surgery: a randomized double-blind study. Anesth Analg. 2007; 105: 1848-1851

3. Boughey, JC, Goravanchi, F, Parris, RN et al. Prospective randomized trial of paravertebral block for patients undergoing breast cancer surgery. Am J Surg. 2009; 198: 720-725

4. Andreae $\mathrm{MH}$, Andreae DA. Regional anaesthesia to prevent chronic pain after surgery: A Cochrane systematic review and metaanalysis. Br J Anaesth. 2013; 111: 711-20

5. Heaney A \& Buggy D. Can anaesthetic and analgesic techniques affect cancer recurrence or metastasis? Brit J Anaesth. 2012; 109: i17i28

6. Garg R. Regional anaesthesia in breast cancer: Benefits beyond pain. Indian J Anaesth. 2017; 61: 369-72

7. ClinicalTrials.gov [Internet]. Sessler D: The Cleveland Clinic (US). 2007 Jan 4 . Identifier NCT00418457, Regional Anaesthesia and Breast Cancer Recurrence; 2007 Jan 4 [cited 2019 Feb 22]. Available from: https://clinicaltrials.gov/ct2/show/study/NCT00418457

8. Blanco R. The "pecs block": a novel technique for providing analgesia after breast surgery. Anaesthesia. 2011; 66: 847-848

9. Kulhari, S. Bharti N, Bala I et al. Efficacy of pectoral nerve block versus thoracic paravertebral block for postoperative analgesia after radical mastectomy: a randomized controlled trial Brit J Anaesth. 2016; 117(3): 382 - 386

10. Wahba, SS \& Kamal, SM. Thoracic paravertebral block versus pectoral nerve block for analgesia after breast surgery. Egypt J Anaesth. 2013; 30: 129-135 